Proc. Indian Acad. Sci., Vol. 87 A (E \& P Sciences), No. 3, March 1978, pp. 47-55, (C) printed in India.

\title{
Total electron content at low latitudes
}

\author{
MALKIAT SINGH, H S GURM, M R DESHPANDE*, \\ R G RASTOGI*, G SETHIA*, A R JAIN**, A V JANVE†, R K RAI†, \\ V M PATWARI $\dagger$ and B S SUBBARAO ${ }^{\dagger} \dagger$ \\ Department of Physics, Punjabi University, Patiala 147002 \\ *Physical Research Laboratory, Ahmedabad 380009 \\ **Indian Institute of Geomagnetism, Bombay 400005 \\ tDepartment of Physics, University of Udaipur, Udaipur 313001 \\ t†AV Parekh Technical Institute, Rajkot 360001
}

MS received 12 August 1977; revised 3 February 1978

\begin{abstract}
Radio beacon from ATS-6 at $140 \mathrm{MHz}$ was used to measure the changes in the polarization angle (Faraday rotation) at Bombay, Rajkot, Ahmedabad, Udaipur and Patiala during October 1975 to July 1976. In this paper, results of diurnal, seasonal and latitudinal variations in total electron content (TEC) derived from these measurements are reported. The amplitude of diurnal peak is found to be higher at Rajkot, Ahmedabad and Udaipur as compared to that at Patiala or Bombay, indicating that the peak of Appleton anomaly in the latitudinal variation of TEC was close to the latitude of Ahmedabad. The diurnal maximum of TEC occurs around the same time during summer and winter months. The peak electron content shows a semiannual variation at all the stations with large values in equinoxes as compared to winter and summer. The TEC at Bombay shows a seasonal anamoly with high values in winter as compared to summer. The paper describes the development of latitudinal anomaly with the time of the day for different seasons. This anomaly is maximum during 1000 to $1800 \mathrm{LT}$ and is located between $12^{\circ}$ and $14^{\circ} \mathrm{N}$ (dip latitude) in summer and equinoxes and at about $10^{\circ} \mathrm{N}$ in winter.
\end{abstract}

Keywords. Ionospheric electron content; equatorial $F$ region anomaly.

\section{Introduction}

The determination of total electron content (TEC) in a vertical column of the ionosphere is of considerable importance for the study of the upper atmosphere as well as for planning the radio communication between an artificial satellite and a ground station. A big spurt of such measurements came with the launching of BE-B and BE-C satellites, orbiting at heights of $1000-1400 \mathrm{~km}$. The measurement of Faraday rotation of radio beacons on low orbiting satellites gives a good snap-shot picture of latitudinal variation of TEC within $10^{\circ}$ north and south of the station. With proper coordination of two or more stations, one can cover a large portion of the ionosphere at one time (Basu and Das Gupta 1967; Tyagi and Mitra 1970; Rastogi et al 1973). The data from these low orbiting satellites do not provide reliable and good estimate for diurnal and seasonal variations of TEC and the transient phenomena like solar flare and sudden commencement cannot be studied with this method. The beacons aboard a geostationary satellite provide a continuous measurement of TEC at a particular location but do not give any idea of the spatial variation of TEC. With the coordination of a number of stations using the same beacons it is possible to have both temporal and spatial variations of TEC. 
Table 1. Coordinates of different stations and other parameters of the propagation path of ATS-6 beacon.

\begin{tabular}{|c|c|c|c|c|c|c|c|}
\hline \multirow[t]{2}{*}{ Station } & \multirow{2}{*}{\multicolumn{2}{|c|}{$\begin{array}{l}\text { Geographic } \\
\text { Long. Lat. }\end{array}$}} & \multicolumn{3}{|c|}{$\begin{array}{l}\text { Sub-ionospheric } \\
\text { height } 350 \mathrm{~km}\end{array}$} & \multirow[t]{2}{*}{$\begin{array}{l}\text { Elevation } \\
\text { angle }\end{array}$} & \multirow[t]{2}{*}{$M(350)=\bar{M}$} \\
\hline & & & $\begin{array}{l}\text { Geo } \\
\text { Long. }\end{array}$ & $\begin{array}{l}\text { hic } \\
\text { Lat. }\end{array}$ & $\begin{array}{l}\text { Dip } \\
\text { Lat. }\end{array}$ & & \\
\hline & ${ }^{\circ} \mathrm{E}$ & ${ }^{\circ} \mathrm{N}$ & ${ }^{\circ} \mathrm{E}$ & ${ }^{\circ} \mathrm{N}$ & ${ }^{\circ} \mathrm{N}$ & - & \\
\hline Bombay & 72.9 & $19 \cdot 1$ & $69 \cdot 8$ & $17 \cdot 8$ & $11 \cdot 7$ & 41.9 & $19 \cdot 51$ \\
\hline Rajkot & $70 \cdot 7$ & $22 \cdot 3$ & $67 \cdot 7$ & 20.8 & $16 \cdot 5$ & $42 \cdot 4$ & $24 \cdot 69$ \\
\hline Ahmedabad & $72 \cdot 6$ & $23 \cdot 0$ & $69 \cdot 4$ & $21 \cdot 5$ & $17 \cdot 1$ & $40 \cdot 3$ & $25 \cdot 77$ \\
\hline Udaipur & $73 \cdot 7$ & $24 \cdot 6$ & $70 \cdot 2$ & $22 \cdot 9$ & $17 \cdot 6$ & $38 \cdot 6$ & $28 \cdot 15$ \\
\hline Patiala & $76 \cdot 4$ & $30 \cdot 3$ & $72 \cdot 1$ & $28 \cdot 2$ & $25 \cdot 2$ & $33 \cdot 3$ & $36 \cdot 72$ \\
\hline
\end{tabular}

TEC measurements using low as well as geostationary satellites have been extensively made in USA, Europe and Japan and comparatively very meagre data exist for low and tropical latitudes. The scientis's in India got an opportunity of studying the radio beacon from a geostationary satellite with the drifting of Intelsat $2 \mathrm{~F} 2$ and Syncom III across our longitudes. With the repositioning of ATS-6 at $34^{\circ} \mathrm{E}$ longitude, a rare opportunity was provided to the scientists in different parts of India for continuously monitoring the beacon for a period of about one year. Titheridge (1966) type polarimeters at $140 \mathrm{MHz}$ were developed at the Physical Research Laboratory, Ahmedabad (Banshidhar et al 1977) and well-coordinated measurements were carried out at a number of institutions in India. The location of these institutions, their coordinates concerned with the direction and sub-ionospheric points for this set of stations are given in table 1 .

It is seen that the elevation angle of the signal at these stations is fairly high in the range of $33^{\circ}-42^{\circ}$. Further, it is known (Rastogi 1960) that in Indian longitudes, the peak of equatorial $F_{2}$ region anomaly lies between the latitudes of $20^{\circ}$ and $25^{\circ}$, thus the present set of stations is very useful in studying the development and variability of equatorial $F_{2}$ region anomaly. The present paper describes the daily, seasonal and latitudinal variations of the TEC in Indian zone.

\section{Data and analysis}

The instruments used and the method of obtaining TEC have been described by Banshidhar et al (1977). Since most of the contribution to the Faraday rotation is from the electrons in the vertical column up to $2000 \mathrm{~km}$, the mean field height is taken to be $350 \mathrm{~km}$ (Titheridge 1972). The values of mean field factor $(\vec{M})$ are given in table 1 .

For absolute calibrations, firstly, the angle between the transmitted signal and local vertical is calculated and then corresponding to vertically transmitted signal in front of yagi antenna, the reading on the chart ts noted. The values of $a$, the angle between the local vertical and spin axis of ATS 6 are $61^{\circ}, 55.3^{\circ}, 55.5^{\circ}, 54.1^{\circ}$ and $48.8^{\circ}$ for Bombay, Rajkot, Ahmedabad, Udaipur and Patiala respectively. From the published 
results (Klobuchar 1975), the initial transmitted polarization angle $\left(\beta_{T}\right)$ at the satellite is taken as $-90^{\circ}$. If $\beta_{r}$ is the angle recorded on the chart when the signal is vertical then the Faraday rotation angle $\Omega_{0}$ corresponding to the zero of the chart is given by:

$$
\Omega_{0}=a-\beta_{T}-\beta_{r}
$$

$\beta_{r}$ was determined to be zero for all these polarimeters. As a check on these calibrations, the final absolute values of TEC were obtained by comparison with occasional passes of the low orbiting satellite Intasat recorded at Ahmedabad and Patiala. The $n \pi$ ambiguity can be very easily settled in these years of low solar activity. The nighttime value of TEC is of the order of $2 \times 10^{16} \mathrm{el} \mathrm{m}^{-2}$, while one $\pi$ rotation means $(5 \cdot 75-10 \cdot 3) \times 10^{16} \mathrm{el} \mathrm{m}^{-2}$ from Patiala to Bombay.

\section{Results}

\subsection{Diurnal variation}

Mean daily variation of TEC was computed for whole of data available from each station and the resultant curves are shown in figure 1. It may be mentioned here that the amount of data for a particular station is fairly complete except for the month of March 1976, when the beacon was put off for certain periods due to power restriction caused by satellite going into earth's shadow during this month.

For any of these stations the electron content reaches a minimum during pre-dawn hour between 0500 and $0600 \mathrm{LT}$ being of the order of $2 \times 10^{16} \mathrm{el} \mathrm{m}^{-2}$. After sunrise the TEC increases at all the stations till it reaches the maximum value in the afternoon hours. The TEC decreases smoothly later with a minimum around pre-dawn hours. The peak of maximum TEC is around 1400-1500 LT at Bombay, Rajkot, Ahmedabad and Udaipur while at Patiala it is around 1300-1400 LT. The TEC at Bombay, Rajkot, Ahmedabad and Udaipur is higher than the TEC at Patiala indicating that Patiala is north of the equatorial anomaly region.

Figure 2 shows the daily variation of TEC averaged over different seasons, i.e., Winter (Nov., Dec., Jan., Feb.,), Equinoxes (Oct., March, April) and Summer (May, June, July) for Bombay, Ahmedabad, Udaipur and Patiala. The occurrence of peak at Patiala (sub-ionospheric dip lat. 25.2) is consistently earlier than the other

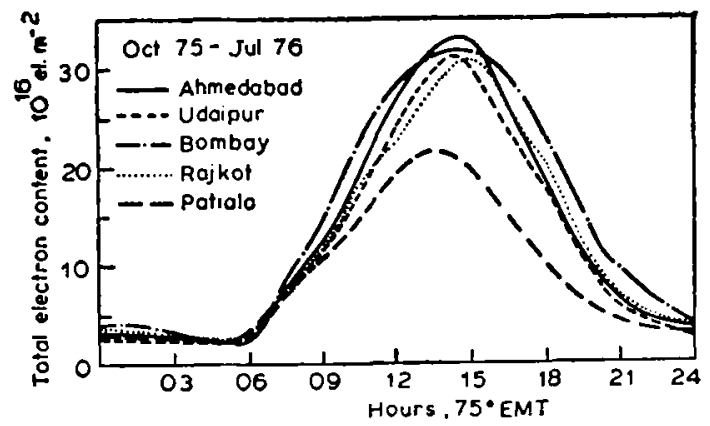

Figure 1. Mean daily variation of TEC, computed for whole of the data available from each station. 


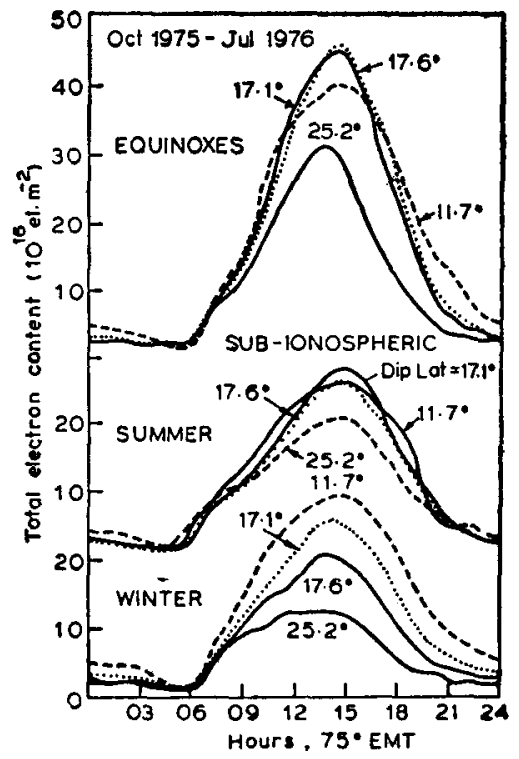

Figure 2. Mean daily variation of TEC averaged over different seasons for Bombay (dip lat. $11 \cdot 7^{\circ} \mathrm{N}$ ), Ahmedabad (dip lat. $17 \cdot 1^{\circ} \mathrm{N}$ ), Udaipur (dip lat. $17 \cdot 6^{\circ} \mathrm{N}$ ) and Patiala (dip lat. $25 \cdot 2^{\circ} \mathrm{N}$ ).

stations in all seasons. The peaks in summer and winter are broad compared with equinoxes at all stations. The minima in summer are earlier by an hour while the maxima are delayed by at least half an hour compared to winter season. In equinoxes the diurnal peaks occur earlier than winter and summer. The diurnal ratio (Maximum TEC/minimum TEC) at these stations for different seasons is given in table 2. The amount of data for Rajkot station is comparatively less hence not included in table 2.

It can be seen from table 2 that the diurnal ratios are highest in equinoxes for any of the stations. The diurnal ratios are higher in winter than summer at Bombay, Ahmedabad, Udaipur while at Patiala converse is true. During winter monthe the ratios show a decrease with increase in latitude while there is no significant latitudinal variation in the summer months. Garriott et al (1970) made similar studies for different solar activities at middle lattitudes and observed that the diurnal ratios for summer are constant whereas for winter the ratio is a function of latitude and solar activity.

Mean monthly values for TEC have been plotted for Bombay, Ahmedabad and Patiala in figures $3 \mathrm{a}$ to $3 \mathrm{c}$. The months have been arranged into two groups, i.e., from October 1975 to March 1966 and from February 1976 to July 1976. This has

Table 2. Diurnal ratio for different seasons.

\begin{tabular}{llccc}
\hline Season & Bombay & Ahmedabad & Udaipur & Patiala \\
\hline Summer & 13 & 14 & 13 & 12 \\
Equinox & 27 & 23 & 23 & 27 \\
Winter & 17 & 16 & 14 & 8 \\
\hline
\end{tabular}


been done to ayoid overlapping of curves and the months of February and March are repeated for comparison. At Bombay (figure 3a) TEC decreases from October through winter months, being minimum in February and again increases with the maximum in the month of March, and again decreases from equinox through summer months. The TEC peak in February 1976 is the lowest among winter months. The

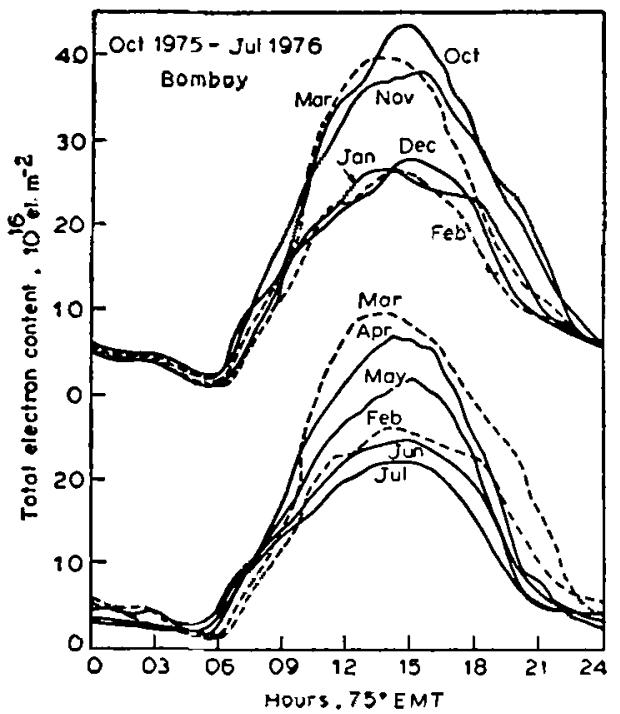

(a)

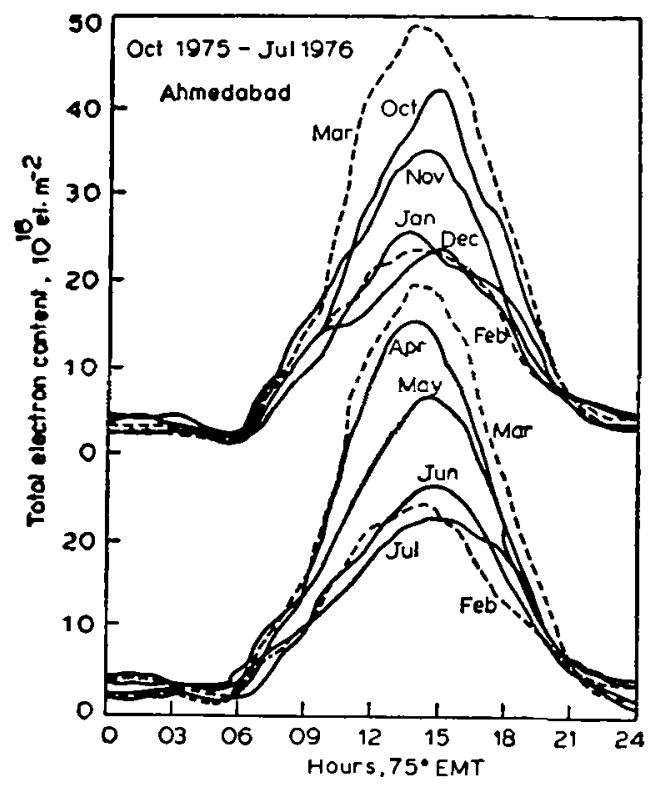

(b)

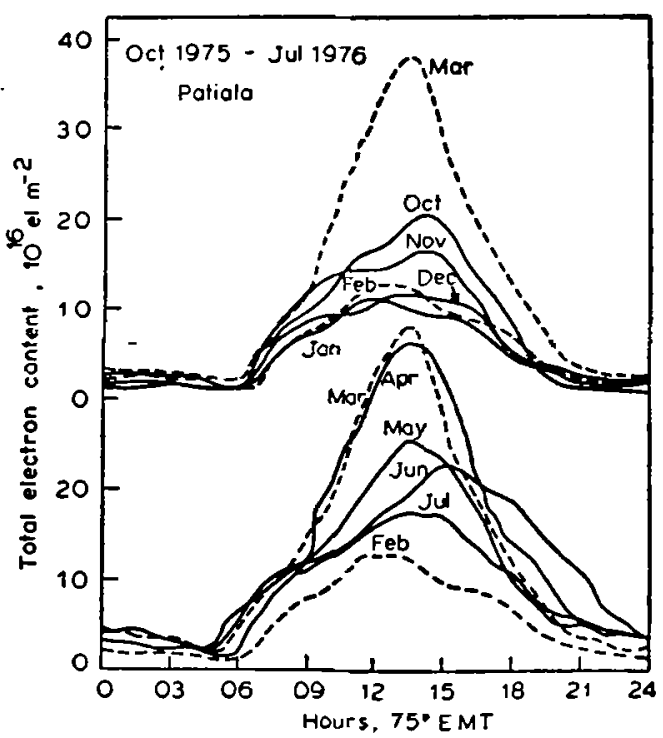

(c)

Figure 3. Mean daily plots averaged on monthly basis for a. Bombay b. Ahmedabad c. Patiala 
peak in July 1976 is lowest among summer months and is also lower than the peak value in February. The diurnal ratio of November is higher than that of May. Comparing the monthly curves of TEC at Ahmedabad (figure 3b), one finds that the afternoon value of TEC is largest in the month of March 1976 and lowest in July 1976, although there is a very small difference in TEC during summer and winter months. At Patiala (figure 3c) the largest value of TEC occurs in March and April 1976. The

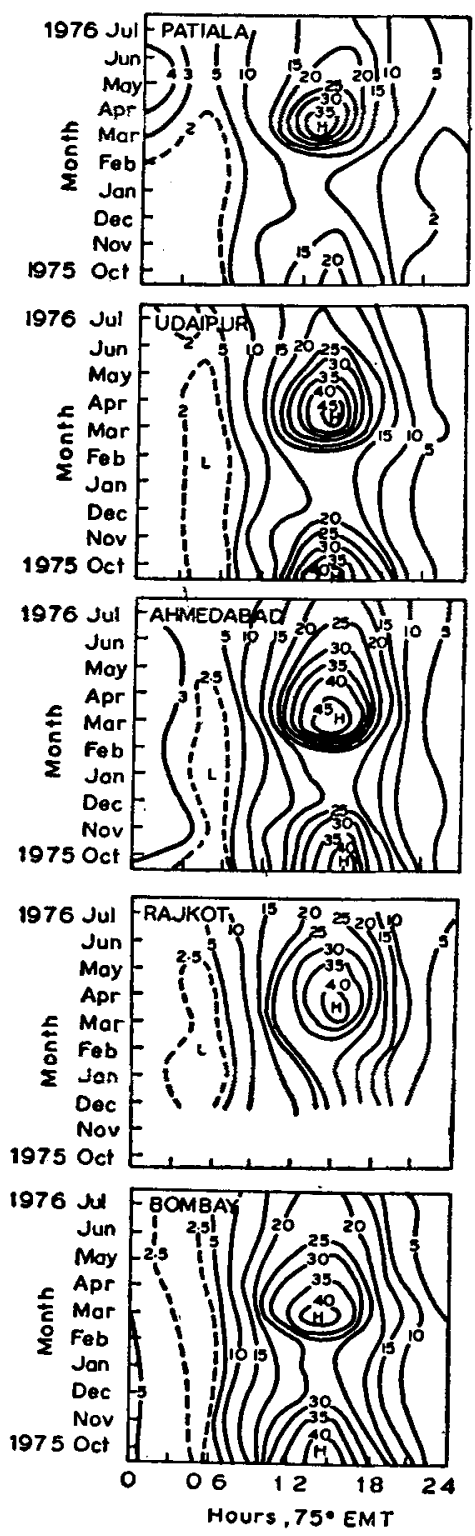

Figure 4. Contour diagrams of TEC on a grid of local time versus months (October 1975 to July 1976) for different stations. 
maximum value of TEC in October 1975 is about half the corresponding value in March 1976. Further, the minimum value occurs in January 1976. Peak TEC values in any of the summer months are considerably higher than the corresponding values of winter months.

The mean hourly values for all 10 months (October 1975 to July 1976) for all the stations were used to compare the contour diagrams of TEC on a grid of local time versus months (figure 4). From this figure it can be noticed that all stations there is a semi-annual variation in electron content, higher in equinox than in winter and summer as reported earlier on the basis of data from low orbiting satellites. The contour map of TEC for Bombay shows that values are higher in winter than in summer while at Patiala the values are higher in summer than in winter. At Ahmedabad the TEC was comparable in winter and summer. Tyagi and Mitra (1970) have shown that the TEC at Delhi was about twice as large in summer as in winter, at Ahmedabad the values were comparable during the two solstices and at Hong Kong the values were higher in winter than in summer. Thus it may be concluded that the winter anomaly in TEC is a feature confined within the latitude zone affected by the equatorial $F$ region anomaly.

\subsection{Latitudinal variation}

The chain of 5 stations covers the equatorial anomaly region. Bombay is below the

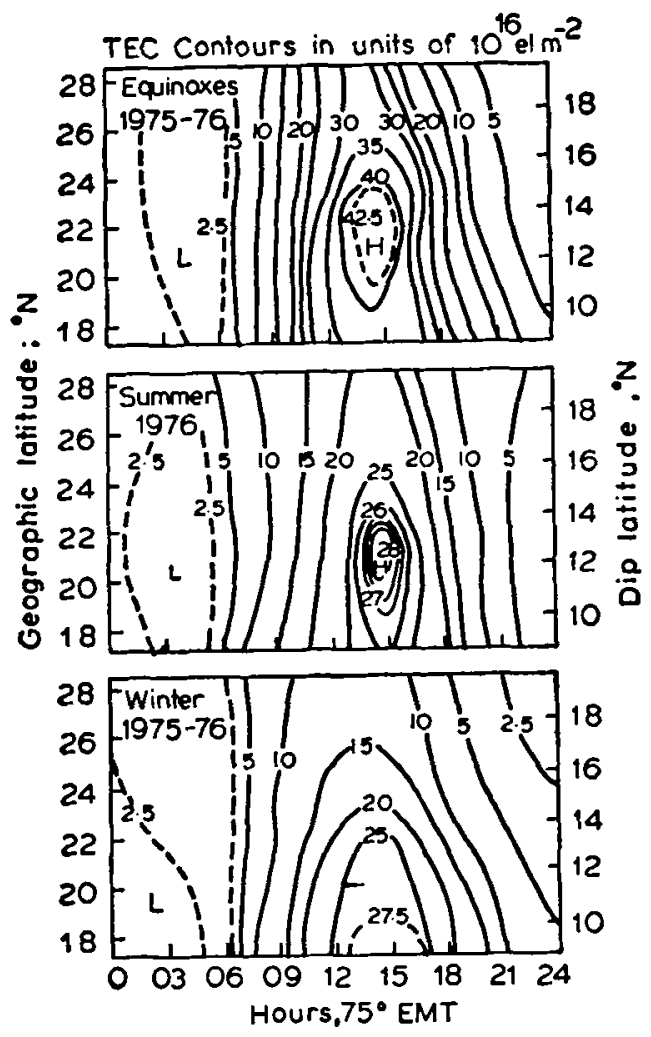

Figure 5. Contour diagrams of TEC on a grid of local time ver sus latitude. 
anomaly peak, Rajkot, Ahmedabad and Udaipur are over the peak while Patiala is out of anomaly peak. In figure 5 are drawn contour diagrams of TEC against local time vs latitudes grid for each of the stations. It is seen that the largest value of TEC (exceeding $42.5 \times 10^{16} \mathrm{el} . \mathrm{m}^{-2}$ ) occurs at the geographic latitude of $23^{\circ} \mathrm{N}$ or dip latitude $14.5^{\circ} \mathrm{N}$ for the Indian zone. During summer months the largest value of TEC was about $29.0 \times 10^{16} \mathrm{el} . \mathrm{m}^{-2}$ at about $1445 \mathrm{LT}$ at the geographic latitude $21 \cdot 5^{\circ} \mathrm{N}$ or dip latitude $13^{\circ} \mathrm{N}$. During winter the maximum value was exceeding $27.5 \times 10^{16}$ el. $\mathrm{m}^{-2}$ at about $1500 \mathrm{LT}$ but location of the peak value has shifted equatorward and is at latitude lower than $17^{\circ} \mathrm{N}$. In other words, the region of maximum TEC is south of Bombay during winter months, it is between Bombay and Ahmedabad during summer and is very close to Ahmedabad during equinoxes. This is consistent with the similar northernmost shift of the region of maximum foF 2 during equinoxes (Rastogi et al 1972). During the later half of the night there does not seem to be any spatial variation of TEC, the values at any place is less than $5 \times 10^{16} \mathrm{el}^{-\mathrm{m}^{-2}}$, the minimum is about $2 \times 10^{16} \mathrm{el} . \mathrm{m}^{-2}$.

\section{Discussion and Conclusion}

The TEC information in and around equatorial anomaly region is severely lacking. This information is of importance to understand dynamical control of the ionosphere by the equatorial electrojet at low latitudes. The present study was aimed to fulfil this objective especially for the Indian sub-continent. In addition detailed behaviour of TEC during different seasons and also during the course of the day over India is discussed. Such investigations are useful for modelling the ionosphere and also for evaluating range and rate errors for tracking satellites. The TEC over India shows a pronounced semi-annual variation with equinoctial peaks. This is suggested to be due to the observed excess of $\mathrm{O} / \mathrm{N}_{2}$ ratio during equinox months (Offerman 1974). Higher $\mathrm{O} / \mathrm{N}_{2}$ ratio not only yields excess production of ionization but also reduces loss rate of electrons. The second process which also could contribute to semi-annual variation in TEC is the strength of the electrojet itself. It is found that the electrojet currents are stronger in equinox months and consequently more ionization is uplifted from the equator and dumped at Ahmedabad latitudes. Further investigations in this direction are under way.

The latitudinal variation of TEC shows equatorial anamoly similar to foF 2 anomaly (Das Gupta and Basu 1971; Rastogi et al 1971, 1973, 1975) over India. This can be explained due to $E \times B$ drifts of ionization at the equator and the subsequent diffusion of the ionization along the field lines. Hence the strength of latitudinal anomaly is greatly controlled by the electrojet strength (Chapman and Rajarao 1965; Rastogi ('t al 1972).

Another important feature to be noted is that the daytime TEC is more during summer months as compared to winter months at higher latitudes (Patiala and Udaipur). Contrary to this TEC values are more in winter at Bombay than in summer. At the anomaly crest (Ahmedabad and Rajkot) the winter and summer values are comparable.

The occurrence of winter anomaly at Bombay during low sunspot years can be the manifestation of the shifting of equatorial anomaly crest towards equator during winter. Thus, it seems that equatorial electrojet strength has a significant control 
over the observed latitudinal and seasonal variations of TEC in the low latitude regions.

\section{Acknowledgements}

The authors are grateful to Professor J A Klobuchar for stimulating discussions during his stay in Ahmedabad. Thanks are also due to $\mathrm{Mr}$ Banshidhar and $\mathrm{Mr} \mathrm{N} \mathrm{M}$ Vadher for the responsibility of developing and fabricating the polarimeters and to $\mathrm{Mr} \mathrm{K} \mathrm{C}$ Patel and Miss Chhaya Shah for their assistance in computational work. The project for constructing number of polarimeters was supported by the Department of Space, Government of India. Thanks are also due to the authorities of all the collaborating institutions for their encouragement.

\section{References}

Banshidhar, Vadher N M and Dsshpande M R 1977 J. Inst. Telecom. Eng. New Delhi 23708 Basu S and Das Gupta A 1967 J. Geophys. Res. 725555

Chapman S and Rajarao K S 1965 J. Atmos. Terr. Phys. 27559

Das Gupta A and Basu S 1971 Indian J. Pure Appl. Phys. 9509

Garriott O K, da Rosa A V and Ross W J 1970 J. Atmos. Terr. Phys. 32705

Klobuchar J A 1975 J. Geophys. Res. 804387

Offerman D 1974 J. Geophys. Res. 794281

Rastogi R G 1960 J. Atmos. Terr. Phys. 18315

Rastogi R G and Sharma R P 1971 Planet Space Sci. 191505

Rastogi R G, Chandra H, Sharma R P and Rajaram G 1972 Indian J. Rad. Space Phys. 1119

Rastogi R G, Sharma R P and Shodhan V 1973 Planet. Space Sci. 21713

Rastogi R G, Iyer K N and Bhattacharyya J C 1975 Curr. Sci. 44531

Titheridge J E 1966 J. Atmos. Terr. Phys. 281135

Titheridge J E 1972 Planet. Space Sci. 20353

Tyagi T R and Mitra A P 1970 J. Atmos. Terr. Phys. 321807 